3) Use respiratory masks during close contact with people, and try to change the masks often.

4) Maintain several meters distance from other pilgrims.

5) Avoid contact with other pilgrims who appear ill.

6) Obtain vaccination (high-risk individuals).

7) Avoid shaking hands and kissing during greetings.

8) Wear mask and gloves during the pilgrimage and touching the shrine.

Also, if individuals appear with signs and symptoms of flu, the following measures should be taken ${ }^{15}$ :

1) Use a mask to cover the mouth and nose.

2) Cover the nose and mouth with their arm/sleeve or a napkin when sneezing or coughing.

3) Placed used napkin or tissue in a plastic bag, then close the bag and throw it in the trash.

Observing such measures can greatly reduce the spread of influenza virus during the Arba'een pilgrimage.

Acknowledgments. This work was supported by the Hamadan University of Medical Sciences.

Financial support. No financial support was provided relevant to this article.

Conflicts of interest. All authors report no conflicts of interest relevant to this article.

\section{References}

1. Pavia A. One hundred years after the 1918 pandemic: new concepts for preparing for influenza pandemics. Curr Opin Infect Dis 2019;32: 365-371.

2. Lee BE, Mukhi SN, Drews SJ. Association between patient age and influenza A subtype during influenza outbreaks. Infect Control Hosp Epidemiol 2010;31:535-537.
3. Álvarez F, Froes F, Rojas AG, Moreno-Perez D, Martinón-Torres F. The challenges of influenza for public health. Future Microbiol 2019;14: 1429-1436.

4. Zhang N, Li Y. Transmission of influenza A in a student office based on realistic person-to-person contact and surface touch behaviour. Int $J$ Environ Res Public Health 2018;15:1699.

5. Chow EJ, Doyle JD, Uyeki TM. Influenza virus-related critical illness: prevention, diagnosis, treatment. Crit Care 2019;23:214-214.

6. Up to 650,000 people die of respiratory diseases linked to seasonal flu each year. World Health Organization website. https://www.who.int/en/newsroom/detail/14-12-2017-up-to-650-000-people-die-of-respiratory-diseaseslinked-to-seasonal-flu-each-year. Published December 14, 2017. Accessed February 18, 2020.

7. Influenza update 359. World Health Organization website. https://www. who.int/influenza/surveillance_monitoring/updates/latest_update_GIP_ surveillance/en/. Published January 22, 2020. Accessed February 18, 2020.

8. Hatami H. History of influenza: pandemics in Iran and the world. Int I Infect 2016;3:e36672.

9. Moghoofei M, Monavari SH, Mostafaei S, et al. Prevalence of influenza A infection in the Middle East: a systematic review and meta-analysis. Clin Respir J 2018;12:1787-1801.

10. Goeijenbier M, van Genderen P, Ward B, Wilder-Smith A, Steffen R, Osterhaus A. Travellers and influenza: risks and prevention. $J$ Travel Med 2016;24:taw078.

11. Aligne CA. Overcrowding and mortality during the influenza pandemic of 1918. Am J Public Health 2016;106:642-644.

12. Shia pilgrims flock to Karbala for Arba'een climax. BBC News website. https:// www.bbc.com/news/world-middle-east-30462820. Published December 14, 2014. Accessed February 18, 2020.

13. Solmaz, N. Possible outbreak of flu after return of Iranian pilgrims from Iraq. The Independent Persian website. https://www.independentpersian. com/node/25811. Published October 22, 2019. Accessed February 18, 2020.

14. Ministry of Health: Influenza casualties reach 9. Islamic Reppublic News Agency. https://www.irna.ir/news/83603379/. Published January 1, 2019. Accessed February 18, 2020.

15. Healthy habits to help prevent flu. Centers for Disease Control and Prevention website. https://www.cdc.gov/flu/prevent/actions-prevent-flu.htm. Published November 7, 2019. Accessed February 18, 2020.

\title{
Applying behavioral frameworks to antimicrobial stewardship
}

\author{
Nisha Thampi MD, MSc ${ }^{1}$ (1), Julia E. Szymczak $\mathrm{PhD}^{2,3}$ and Jerome A. Leis MSc, MD ${ }^{4,5}$ \\ ${ }^{1}$ Department of Pediatrics, Children's Hospital of Eastern Ontario, University of Ottawa, Ottawa, Ontario, Canada, ${ }^{2}$ Department of Biostatistics, Epidemiology and \\ Informatics, Perelman School of Medicine, University of Pennsylvania, Philadelphia, Pennsylvania, United States, ${ }^{3}$ Division of Infectious Diseases, Children's \\ Hospital of the University of Pennsylvania, Philadelphia, Pennsylvania, United States, ${ }^{4}$ Department of Medicine, Sunnybrook Health Sciences Centre, Toronto, \\ Ontario, Canada and ${ }^{5}$ Department of Medicine and Centre for Quality Improvement and Patient Safety and University of Toronto, Toronto, Ontario, Canada
}

To the Editor-The effectiveness of healthcare improvement initiatives is highly dependent on the social, psychological, organizational and cultural dynamics of clinical settings. ${ }^{1,2}$ Historically, in antimicrobial stewardship, most interventions have been broadly implemented without taking these important contextual factors into account, despite research demonstrating the importance of adaptation to the local context. ${ }^{3,4}$ Furthermore, the recommended metrics for assessing the impact of interventions do not take into consideration the dynamics between the clinician and

Author for correspondence: Nisha Thampi, Email: nthampi@cheo.on.ca

Cite this article: Thampi N, Szymczak JE, and Leis JA. (2020). Applying behavioral frameworks to antimicrobial stewardship. Infection Control \& Hospital Epidemiology, 41: 628-630, https://doi.org/10.1017/ice.2020.40 antimicrobial stewardship team, making it more difficult to predict the long-term success of a program. ${ }^{5}$ Existing behavior-change models can be applied to determine how the intended recipient of an intervention might respond to initiatives that seek to change behavior in order to optimize the uptake and sustainability of antimicrobial stewardship interventions.

Prochaska and DiClemente's transtheoretical model (TTM) is one such framework. It consists of 5 stages that conceptualize how people change their health behavior. ${ }^{6}$ In the initial stage, precontemplation, the individual does not intend to take action within the next 6 months. In stage 2 , contemplation, action is intended within the next 6 months. Stage 3 is preparation, in which action is intended within the next 30 days; stage 4 is action, in which 


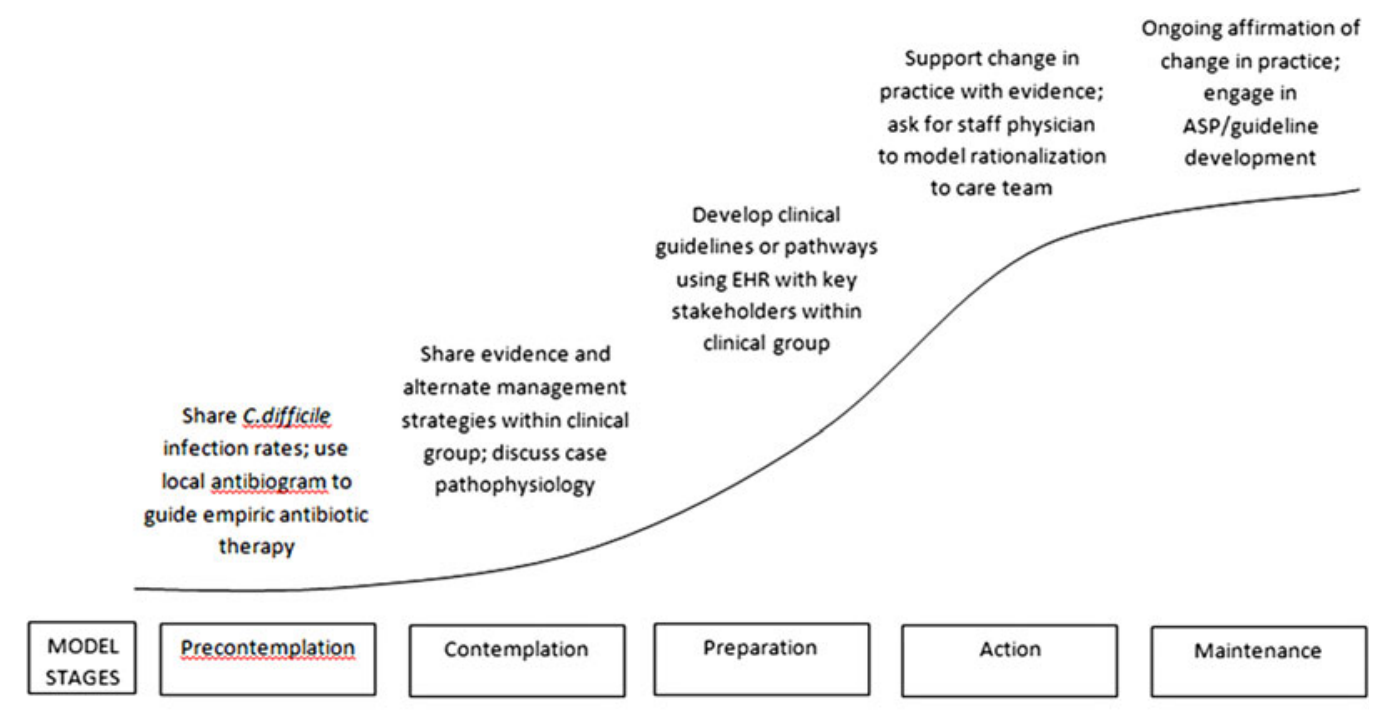

Fig. 1. Transtheoretical model with stages of change and application to discussions of antimicrobial misuse.

ASP: antimicrobial stewardship program; EHR: electronic health record

behavior has recently changed; and stage 5 is maintenance, in which behavior changes are sustained for $>6$ months.

Although this model was initially used to understand behavior change associated with smoking cessation, it has been broadly applied to infection prevention and control, demonstrating both the value in understanding motives among clinicians to adhere to standard precautions and success with stage-matched interventions aimed toward improving adherence to standard precautions and hand hygiene compliance. ${ }^{7,8}$ Figure 1 highlights the practical application of the TTM during an antimicrobial stewardship encounter between a frontline clinician and an antimicrobial stewardship clinician. For example, when the clinician may not perceive a need to decrease his/her fluoroquinolone use (precontemplation stage), the antimicrobial stewardship interaction highlights recent local cases of Clostridioides difficile that followed fluoroquinolone use. Discussions that review case pathophysiology, including the evidence for an infection, and discussions that raise consciousness about peer prescribing practices can support a clinician who is contemplating a change in their prescribing behaviors (contemplation stage). In contrast, the clinician who already self-initiates reassessment of antimicrobial therapy (action stage) would not benefit from reviewing the rationale for stewardship because they are already committed to making behavioral changes. Rather, affirmation on rounds and engagement in guideline development would reinforce the changes already being made and move the clinician into the maintenance stage.

For behavior change to occur, the TTM posits that clinicians must pass through all stages of change. Failure to tailor antimicrobial stewardship initiatives to the recipient's stage of change may delay progress or even cause regression to earlier stages. When behaviors are easy to change and resistance is low, the specific stage of change may matter very little. In such situations, brief interventions and messages may be all that are needed to help clinicians progress through the stages. In contrast, where the change is perceived as difficult and is associated with resistance, there is a greater need to provide deliberate messaging and individualized, stagematched interventions.
The effectiveness of antimicrobial stewardship interventions has been studied widely, yet significant knowledge gaps exist related to the impact of clinicians' readiness to adopt these practice changes on antimicrobial stewardship outcomes. Because success of the same antimicrobial stewardship intervention can vary across clinical networks, metrics that take into account the dynamics between prescribers and the antimicrobial stewardship team can provide insight into how well an intervention will be incorporated into the local culture of practice. ${ }^{4,5,9,10}$ Further research identifying, measuring, and accounting for stages of behavioral change in the evaluation of antimicrobial stewardship improvement strategies will provide insight into how to adapt and integrate these initiatives across various healthcare settings.

Financial support. No financial support was provided relevant to this article.

Conflicts of interest. All authors report no conflicts of interest relevant to this article.

\section{References}

1. Coles E, Wells M, Maxwell M, et al. The influence of contextual factors on healthcare quality improvement initiatives: what works, for whom and in what setting? Protocol for a realist review. Syst Rev 2017;6:168.

2. Ovretveit J. Understanding the conditions for improvement: research to discover which context influences affect improvement success. BMJ Qual Saf 2011;20 suppl 1:118-i23.

3. Lorencatto F, Charani E, Sevdalis N, Tarrant C, Davey P. Driving sustainable change in antimicrobial prescribing practice: how can social and behavioural sciences help? J Antimicrob Chemother 2018;73:2613-2624.

4. Sikkens JJ, van Agtmael MA, Peters EJG, et al. Behavioral approach to appropriate antimicrobial prescribing in hospitals: the Dutch Unique Method for Antimicrobial Stewardship (DUMAS) participatory intervention study. JAMA Intern Med 2017;177:1130-1138.

5. Moehring RW, Anderson DJ, Cochran RL, et al. Expert consensus on metrics to assess the impact of patient-level antimicrobial stewardship interventions in acute-care settings. Clin Infect Dis 2017;64: 377-383.

6. Prochaska JM, Prochaska JO, Levesque DA. A transtheoretical approach to changing organizations. Adm Policy Ment Health 2001;28:247-261. 
7. Livshiz-Riven I, Nativ R, Borer A, Kanat-Maymon Y, Anson O. Nursing students' intentions to comply with standard precautions: an exploratory prospective cohort study. Am J Infect Control 2014;42:744-749.

8. Pontivivo G, Rivas K, Gallard J, Yu N, Perry L. A new approach to improving hand hygiene practice in an inner city acute hospital in Australia. Healthcare Infect 2012;17:57-63.

9. Charani E, Ahmad R, Rawson TM, Castro-Sanchez E, Tarrant C, Holmes AH. The differences in antibiotic decision-making between acute surgical and acute medical teams: an ethnographic study of culture and team dynamics. Clin Infect Dis 2019;69:12-20.

10. Elango S, Szymczak JE, Bennett IM, Beidas RS, Werner RM. Changing antibiotic prescribing in a primary care network: the role of readiness to change and group dynamics in success. Am J Med Qual 2018;33: $154-161$.

\title{
Food service: An overlooked potential vector for hospital infection
}

\author{
John D. Carter Jr (1)
}

Carter Exterminating Company, Cleveland, Ohio

To the Editor-In more than 25 years of working with hospitals to eliminate pests, I have observed an increasingly superficial approach to reducing the sources of sustenance for insects ${ }^{1}$ and rodents ${ }^{2}$ that can serve as vectors for disease-causing organisms. Conditions have degenerated from the time when hospitals had dedicated food service professionals as employees. Now this work commonly is done by contractors without the same knowledge, commitment, ${ }^{3}$ or hospital-specific training.

Hospitals largely rely on topical agents for cleaning that address the surface contaminants but not the residual contamination. Instead of eliminating the hidden food-decaying organisms that attracts flies, hospitals now use electrocution devices that introduce and disseminate exploded insect bodies into HVAC systems, further contaminating surgical theatres, ICUs, and patient rooms. Figure 1 provides examples of the many potentially diseasetransmitting conditions I have observed.

Certain species of filth flies can travel for miles within a 24-hour period searching an entire facility for decaying organic matter for additional propagation. ${ }^{4}$ Adult fruit, drain, or moth flies are prolific breeders, resulting in a wide area of invasion far from the original breeding sites. Therefore, all occurrences of degenerating organic debris can be original or satellite breeding opportunities.

Filth flies are capable of breeding in more types of materials than any other structure-infesting fly. In buildings, they be may found breeding in drains, trash containers, dumpsters, rotting produce, recycle bins, grease traps, garbage disposals, crawl spaces, and any site where moist organic matter can accumulate for a few days or longer. Fly larvae have been found in the open wounds of patients, and even in the mouths of intubated patients (I have personally seen this).

Food service areas present the number-one opportunity to prevent disease. Food contaminates! It attracts insects and other pests. We need to understand this potential for contamination when storing and preparing food and utensils. Hospital buildings are like our own human bodies. The very systems that support our lives also are vulnerabilities for infection. Bricks and mortar can protect the hospital like the integument protects the body. Heating ventilation and air conditioning (HVAC) systems can exclude or admit pathogens in the same way as the human respiratory system. Food-

Author for correspondence: John D. Carter, E-mail: john@carterexterminating.com Cite this article: Carter JD. (2020). Food service: An overlooked potential vector for hospital infection. Infection Control \& Hospital Epidemiology, 41: 630-631, https:// doi.org/10.1017/ice.2020.39 waste management systems can prevent or allow viruses or bacteria, just like the digestive system.

Pests are attracted to buildings in the same way that diseasecausing pests are attracted to humans. We invite them in with smells and opportunity. We give them a home in decaying matter. We use a symptom-based approach instead of a thorough evaluation and investigation. When we do not appreciate and address these attractions, we end up with pests of all sorts and increased potential for disease.

Pesticide use is regulated and cannot be a substitution for sanitation and maintenance. In situations where organic debris are degenerating, topical pesticide applications degenerate much faster than their intended label application parameters, and anti-pest baits are mitigated by food competition.

A 3-word definition of food sanitation is protection from contamination. With this in mind, all hospital functions and operations must be included in a sanitation program. All food products must be protected from contamination from the receiving dock (and before), right through distribution and removal. Sanitation is a dynamic and ongoing function and cannot be sporadic. When embedded in a healthcare facility with a special functions (eg, surgical theatre, pharmacy, dialyses care unit, etc), it becomes even more critical. Adequate cleaning and maintenance are crucial

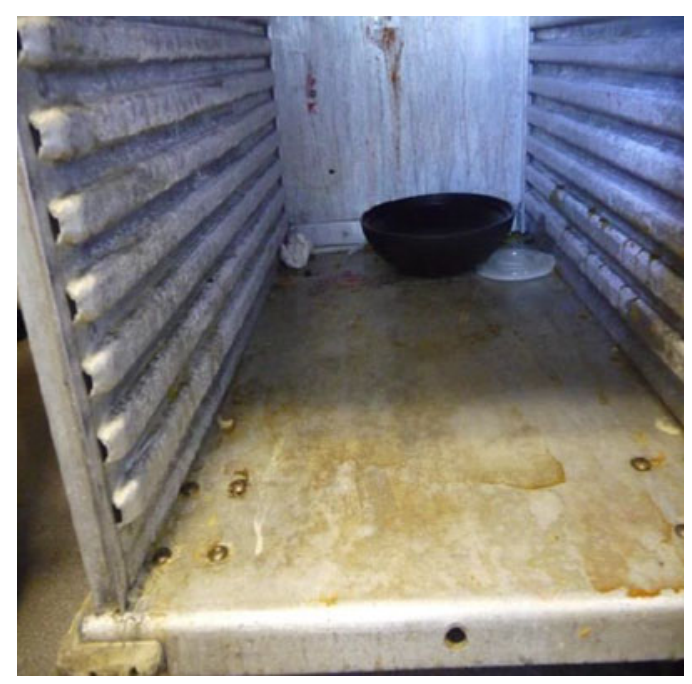

Fig. 1. Patient floor stationed food tray cart: satellite fly proliferation site. 